\title{
Vejez y vida cotidiana en tiempos de pandemia: estrategias, decisiones y cambios
}

\section{Aging and daily life in pandemic times: strategic, decisions and changes}

\author{
Paulina Osorio-Parraguez' \\ https://orcid.org/0000-0002-6438-3712 \\ posorio@uchile.cl \\ Pamela Jorquera' \\ https://orcid.org/0000-0002-2042-6733 \\ pjorquera@facso.cl \\ Matías Araya Tessini ${ }^{\prime}$ \\ https://orcid.org/0000-0002-1591-7159 \\ matias.arayat@gmail.com \\ I Universidad de Chile - Santiago de Chile, Chile
}




\title{
Resumen
}

En el presente artículo se presentan experiencias de personas mayores que muestran la diversidad en la vida cotidiana en la vejez durante la pandemia por Covid-19 en Chile. Para ello se aplicaron entrevistas a distancia a una mujer, a un hombre y a una pareja de personas mayores de distintas condiciones socioeconómicas y etarias. Los resultados muestran una serie de estrategias desplegadas para sobrellevar los cambios y alteraciones de su vida diaria, en el ámbito laboral, afectivo, económico, residencial y familiar. Se concluye que las personas mayores poseen distintas fortalezas y capacidad de agencia, adquiridas a partir de su experiencia biográfica, las cuales les permite afrontar la crisis sociosanitaria, desde su posición como población vulnerable y de alto riesgo. Sus estrategias no sólo se encuentran marcadas por su condición de vejez, sino que también están cruzadas por la posición social, condición laboral, género y residencial.

Palabras clave: vejez; pandemia; agencia; vida cotidiana.

\begin{abstract}
This article exposes experiences of older people that show the diversity of the everyday lifestyle at the old age during the COVID-19 pandemic in Chile. Virtual qualitative interviews were conducted with to a woman, a man and a couple of old age people of different age and socioeconomical conditions. The results show a series of strategies deployed to overcome the changes and the transformation of their everyday life: job, affective, economical, residential, and familiar. It is concluded that older people have different strengths and agency capacities, acquired from their biographical experiences, which allows them to face the sociosanitary crisis, from their position as vulnerable and of high-risk population. Their strategies are not only marked by their old age condition, but also, they are crossed by the social, laboral, gender and residential position.
\end{abstract}

Keywords: aging; pandemic; agency; daily life. 


\section{Introducción}

A finales del 2019 el mundo se vio sacudido por el surgimiento del Covid-19. Su alta capacidad de contagio provocó su rápida propagación, siendo declarada pandemia por la Organización Mundial de la Salud (OMS) a mediados de marzo del 2020. Muchos países adoptaron distintas medidas sociosanitarias para disminuir los contagios en la población y el colapso de los sistemas de salud, entre las que destaca el confinamiento a través de la implementación de cuarentenas.

En Chile el primer caso de Covid-19 se da a conocer el 3 de marzo, veinte días después se decreta toque de queda nocturno y cuarentena total en algunas zonas del país. La OMS (World Health Organization, 2020) establece que las personas mayores se encuentran entre los grupos de mayor riesgo a desarrollar síntomas graves. En esta misma línea, Huenchuan (2020) también señala que el aislamiento social y la soledad tendrá repercusiones en la salud física y emocional de las personas mayores.

Mundialmente asistimos a un proceso de envejecimiento de la población y, Chile no es la excepción. La población mayor de 65 años representa el 16,2\% de los habitantes (Instituto Nacional de Estadística, 2017). De la misma forma, se espera que para el 2050 ese número aumente a un $28,2 \%$. Frente a esta realidad demográfica, Chile enfrenta importantes desafíos. Cabe destacar que para la comprensión integral del proceso de envejecimiento y de la vivencia de la vejez, debe reconocerse el componente social y cultural que la define. Esto permite comprender que muchas de las situaciones de exclusión o vulnerabilidad social a la que se enfrentan las personas mayores dependen del contexto social más que de una característica propia de ese grupo etario.

Esto se relaciona con su designación como población vulnerable en el marco de la pandemia Covid-19. En esta línea, distintos estudios han investigado los efectos del aislamiento social durante la pandemia en la población en general (Cervio, 2020), y en las personas mayores en específico (Armitage; Nellums, 2020; Berg-Weger; Morley, 2020; Cataldi, 2020; Jones, 2020). Desde la psicología Scholten et al. (2020) aborda la problemática de las personas mayores en el contexto latinoamericano y advierte sobre el mayor riesgo de que desarrollen problemas ligados a salud mental, debido a su condición como grupo de riesgo, y su dificultad para adoptar nuevos hábitos cotidianos ante la irrupción 
de sus rutinas. Del mismo modo, la socióloga Xenia Jones (2020) afirma que, en el caso del Reino Unido, el aislamiento y la soledad acrecentada a causa de las medidas de confinamiento podrían potenciar las ya elevadas cifras de suicidios de personas mayores en el país. Producto de esto, ambas investigaciones destacan la importancia de fomentar el aprendizaje y la inclusión digital en las personas mayores, en consideración de la gran relevancia que adquiere la tecnología al momento de comunicarse con el entorno social y familiar en tiempos de aislamiento.

Desde la epidemiología Armitage y Nellums (2020), concuerdan con la importancia que adquiere la tecnología y la comunicación en línea para afrontar los problemas de aislamiento y soledad en el grupo de personas mayores, pero agregan que no solo en la salud mental habrá repercusiones producto del confinamiento, sino que también puede aumentar el riesgo de padecer y empeorar cuadros médicos debido a la disminución de estímulos físicos y sociales.

El antropólogo Palacios (2020) aborda el surgimiento de conflictos en la esfera doméstica en México producto de la obligación que supone el confinamiento por compartir mayor tiempo y espacio entre personas que habitan un mismo hogar. Este hecho que caracteriza como un reencuentro y redescubrimiento familiar implica, para las personas mayores, la necesidad de buscar estrategias que promuevan relaciones sanas en un contexto de convivencia forzada. Afirma que en este panorama de convivencia existe una importante diferencia de vulnerabilidad entre viejos jóvenes de menos de 75 y quienes superan esta edad, debido al mayor nivel de autonomía, comunicación y redes de apoyo del primer segmento. Desde otra perspectiva, la antropóloga colombiana Berena Torres-Marín (2020) advierte sobre el peligro del edadismo en medidas preventivas tomadas por distintos países en pos de proteger a las personas mayores del virus. De acuerdo con la autora, el confinamiento obligatorio focalizado en las personas mayores se trataría de una generalización que establece un trato desigual y discriminatorio, que desconoce la autonomía y capacidad de autocuidado de las personas mayores. Esta generalización tendería, a la vez, a enfatizar los riesgos de la pandemia en aspectos biológicos individuales, minimizando la importancia a nivel epidemiológico de la desigualdad social y las condiciones precarias de vida que influyen de manera significativa a la vulnerabilidad que se encuentra sometida la población más pobre de la sociedad. 
A conclusiones similares se aproxima la investigación desarrollada por Fuentes-García y Osorio-Parraguez (2020) en el contexto chileno, que desde un enfoque de curso de vida y desigualdades analizan el lugar de las personas mayores en pandemia. Aseguran que las formas cotidianas de interconexión de las vidas de las personas mayores se han transformado, a nivel social y simbólico, desde relaciones recíprocas e interdependientes a relaciones unidireccionales y dependientes, posicionándoles como simples receptores. Este escenario ha sido propiciado por diferentes medidas diseñadas e implementadas únicamente desde la premisa de su condición de vulnerabilidad biológico-cronológica, invisibilizando su condición de sujeto con una biografía vital que dispone de capacidad de agencia y autocuidado. La crisis por Covid-19 en Chile profundizó las desigualdades ya existentes en la vejez y develó la real situación de precariedad de las condiciones de vida de las personas mayores bajo el modelo económico neoliberal. Por esto, afirman, existe la urgencia de transformar la concepción de fragilidad acerca de la vejez hacia el reconocimiento como una etapa dinámica y diversa, situada social, política y territorialmente.

Simone Dourado (2020), menciona distintos artículos que han reflexionado, desde las ciencias sociales, acerca de cómo la pandemia se ha convertido en un escenario que ha favorecido la profundización e intensificación de estigmas en torno a la vejez (Beltrão, 2020; Henning, 2020; Pait, 2020). En específico, Dourado (2020) realiza una crítica al uso del término grupo de riesgo, noción que ha sido utilizada anteriormente en pandemias como el VIH y que tuvo como resultado el desarrollo de conductas y prácticas discriminatorias hacia grupos específicos de personas. La exclusión social generada en el contexto del VIH mantiene un paralelismo con la situación de las personas mayores en la pandemia por Covid-19, pues el riesgo, asegura Dourado, es una categoría problemática que conduce a reiteración de estereotipos sociales, por lo que resulta más conveniente la consideración de las características de cada individuo para evaluar su grado de vulnerabilidad ante el virus. Por último, advierte sobre el conflicto que han suscitado las medidas de aislamiento social, llamando a que las personas mayores se mantengan confinadas en sus hogares, que han estancado diversas luchas desarrolladas por este grupo poblacional con el fin de conquistar derechos que garanticen su inclusión y participación en la vida pública de la sociedad. 


\section{Conceptos claves y enfoque teórico}

En el campo de la investigación científica, la vejez se nos presenta como un concepto multidimensional. Por esto, se hace necesario identificar un marco contextual y disciplinar al momento de su definición. Desde un enfoque etnográfico y biográfico, comprendemos la vejez y el proceso de envejecimiento, desde la articulación de lo subjetivo y lo social. Vale decir, "como una construcción biográfica-individual e histórica-cultural” (Osorio, 2006, p. 12).

La lectura del concepto de agencia lo hacemos desde Archer (2003). La autora esquematiza el concepto a partir de: i) reflexividad, que la define como la capacidad de desplegar tácticas, estrategias y alternativas inmediatas frente a obstáculos que se presenten; ii) memoria o registro histórico de los agentes y, iii) pensamiento racional y eficaz de causalidad, que lo define como el proceso de confección de una planificación perdurable o proyecto que calcula medios y fines. El abordaje etnográfico de la investigación permitió acceder a la reflexividad de las personas mayores en un contexto sociosanitario de pandemia por Covid-19.

Relacionado con el concepto de agencia consideramos el concepto de estrategia desde el pensamiento de Bourdieu (Wilkis, 2004). Este autor define estrategia como "acciones objetivamente orientadas a fines, que bien no pueden ser los fines subjetivamente buscados". Este abordaje permite pensar la agencia sin un imperativo racional, es decir que los sujetos actúen con fines definidos de forma clara y anticipada. De tal forma, el concepto de estrategia articulado con el de agencia ofrece aproximarnos a la comprensión de la vida cotidiana de las personas mayores desde un enfoque que incorpore la potencialidad creadora e innovadora presentes en ellas. En esta misma línea teórica (Bourdieu, 1997), comprendemos que las personas mayores poseen una serie de recursos o capitales -económicos, culturales, sociales y simbólicos- a través de los cuales se posicionan dentro de una estructura social, y despliegan ciertas estrategias en su vida cotidiana.

El presente artículo busca mostrar las diversas formas en las que se expresa la vida cotidiana en tiempos de pandemia en personas mayores, enfatizando los procesos de agenciamiento y las diversas estrategias desplegadas durante la vejez para lidiar con los distintos escenarios cotidianos que surgieron a partir del aislamiento social y confinamiento obligatorio en sus hogares, lo cual implicó la discontinuidad y transformación de actividades que formaban parte de sus rutinas diarias. 


\section{Metodología}

La metodología aplicada para este estudio fue de carácter cualitativa e inductiva. La producción de información se basó en entrevistas a distancia. En algunos casos la técnica se aplicó a través de llamada telefónica, videollamada y, en otro a través de una plataforma virtual. La muestra fue intencionada, definiendo criterios de diversidad de género, territoriales, de residencia, socioeconómico y etarios. Se trabajó con tres casos para la producción de microrelatos etnográficos de experiencia en pandemia en la vejez, de una población vulnerable y definida de alto riesgo en la crisis sociosanitaria. A través de cada caso, se busca comprender de qué forma se vive la vida cotidiana en confinamiento y la diversidad del saber hacer en el cruce de vejez y pandemia.

$\mathrm{Al}$ tratarse de entrevistas no presenciales, se aplicó un consentimiento informado oral al inicio de cada encuentro, donde se comunicaban las características del estudio y sus aspectos éticos. Toda esta información quedó registrada en la grabación de las entrevistas.

\section{Resultados}

A continuación, se presentan tres relatos etnográficos de personas mayores que han desplegado una serie de estrategia en tiempos de pandemia y cómo este contexto sociosanitario marca discontinuidades en sus vidas cotidianas.

\section{Gema y Lalo: "No nos preparamos en términos de largo plazo; nos preparamos para una contingencia"}

Al momento que se declara la pandemia del Covid-19, Gema y Lalo estaban volviendo de sus vacaciones de verano. Su retorno a la capital les esperaba con diversas actividades y proyectos a realizar. Habían decidido cambiarse de casa y programado un viaje para visitar a sus amistades en el extranjero. La pareja participaba activamente en diversas actividades comunitarias y sociales. Desde febrero ya se habían informado de algunos casos de Covid-19 en el mundo y asumieron que llegaría también a nuestro país. Sin embargo, reconocen que "nunca nos pusimos en la perspectiva que iba a ser de las dimensiones 
que ha tomado hoy en día en Chile... No nos preparamos en términos de largo plazo; nos preparamos para una contingencia".

Al poco tiempo, las presiones familiares los llevan a "decidir" ir a pasar el confinamiento en su casa en la costa. Siempre pensando que sería una situación pasajera, que la significaron como una extensión de sus recientes vacaciones en ese mismo lugar. Por lo tanto, su traslado no tuvo grandes preparativos, pensando que no estarían más de tres semanas. La presencia familiar en su vida cotidiana se hacía notar a pesar del distanciamiento físico y geográfico: “.... y cuando la familia vio que los abuelos estaban a salvo, por lo menos en un lugar aislado, bajaron la presión, pero instalaron una barrera que no podíamos ir ni siquiera a la esquina", relata Lalo, agregando que ya llevan cuatro meses sin ver a nadie. Reflexionan sobre eso, y reconocen que el lugar más seguro para ellos para evitar un posible contagio era estar efectivamente en un lugar aislado, sin ver a nadie. Ahora se sienten protegidos por ese mismo aislamiento y la posibilidad de moverse por el entorno natural de la zona más libremente.

Su vida cotidiana en las primeras semanas y, en las sucesivas, se configura sobre la base de una serie de actividades que habían dejado pendientes por falta de tiempo. Ahora cuentan con ese tiempo propio, que les provee el confinamiento; se han inscrito en diversos cursos y talleres a distancia sobre la contingencia política o social del país. Esto no solo por el conocimiento y manejo de tecnologías que poseen, sino también por sus capitales sociales, culturales y simbólicos, acumulados a lo largo de sus cursos de vida. A medida que transcurrían las semanas, el aislamiento y el confinamiento comienzan a ser experimentado de otra forma. La pareja recuerda que "al inicio, para mí, fue bastante liberador. Además, dejamos de manejar, dejamos de perder el tiempo andando en auto, dejamos de desplazarnos; fue un periodo sin ninguna obligación, o sea, el uso del tiempo para uno era muy grande". El uso del espacio también va configurando su vida cotidiana, que no solo la viven al interior de la casa, sino también en el jardín y al aire libre. Reconocen la tranquilidad de estar en un entorno natural con bosque y mar. Esos espacios son ocupados diferenciadamente por la pareja: ella, adentro en el escritorio y él afuera, en el huerto. La cocina es el principal espacio de interacción durante el día.

Asumen que las responsabilidades domésticas y de subsistencia las tienen que realizar solos, reflotando estrategias adquiridas a lo largo de la vida. 
La experiencia de asilo y posterior exilio a un país de Europa durante el régimen militar en Chile, les proveen de las herramientas y la fortaleza que requieren para el día a día. Si bien, pertenecen a la definida población de riesgo en pandemia, a sus 70 años de vida ya han tenido un proceso de socialización hacia las discontinuidades y situaciones de crisis: "Por la vida habíamos vivido situaciones de emergencia, yo estuve asilado en la embajada, con situaciones parecidas a ésta, en aislamiento, donde te apropias del espacio y generas rutinas, buscas cómo abastecerse", generando redes de apoyo y estrategias. En la actualidad salen cada mes y medio a hacer compras de alimentos al pueblo más cercano. Para eso se preparan y toman todos los resguardos necesarios, de tal forma de reducir al máximo el riesgo de un posible contagio. También lo viven como una experiencia que rompe con la rutina del encierro.

A medida que avanza la cuarentena y pasan las semanas y los meses, el distanciamiento de la familia se va dejando notar y en términos emocionales se va haciendo más complicado. Para Gema y Lalo, también ha sido una experiencia nueva el hecho de vivir solos tanto tiempo; si bien llevan 47 años casados, "la verdad es que nunca habíamos pasado tanto tiempo juntos, así 24 horas al día juntos; por nuestros trabajos pasábamos tiempo fuera o en el exilio, teníamos mucha gente que pasaba por nuestra casa. Entonces estar los dos solos, cada uno consigo mismo, eso es una novedad total". El aislamiento los ha llevado a re-pensarse, re-crearse como pareja, a hacer más cosas juntos.

El tema de la incertidumbre de lo que va a pasar, es algo que está presente en su reflexión, junto con preguntarse en qué momento vamos a salir de esto o en qué momento se podrán resolver los asuntos pendientes. Esa incertidumbre se vive desde un sentido de realidad, sabiendo que en el aquí y en el ahora no lo podrán resolver.

\section{Rosita: "Me aprovecho de mis vecinos"}

Rosita tiene 79 años, vive sola en una comuna populosa de la capital. Rosita es contadora y trabaja desde que tenía 20 años. Mucho tiempo lo hizo en una empresa, pero después de tener diferencias con sus patrones, decidió renunciar e iniciar su propia empresa junto con su amiga Teresa. Si bien se jubiló a los 54 años, continuó trabajando para poder costear sus gastos los cuales aumentaron con el ingreso de su única hija a la Universidad. Actualmente continúa 
trabajando de forma menos intensa, situación que le agrada mucho debido a que señala que lleva mucho tiempo haciéndolo.

De esta manera, la pandemia la encontró trabajando, en un comienzo, cuando todavía no se decretaba la cuarentena obligatoria en la comuna donde reside, continuó con su rutina de trabajo, es decir, trasladándose a la casa de Teresa dos veces por semana. Una vez que se decretó la cuarentena obligatoria se quedó en su casa, coordinándose con Teresa para llevar a cabo las labores por teléfono e internet.

Al ser considerada población de riesgo por su edad, decidió enfrentar la cuarentena y la pandemia sola en su casa. Si bien vive sola en su departamento, antes de la pandemia se visitaba constantemente con su hija y la familia de esta. Así todos los domingos se dirigía a la casa de su hija para pasar un tiempo juntas. Esta situación fue descontinuada por la pandemia, decidiendo mantener el distanciamiento. Rosita señala que es más tranquilizador para ella mantenerse alejada de su hija y nieta, tanto para su protección como la de ellas. Esto lo hace por precaución puesto que declara que "mientras más miedo se tiene, más se atrae el bicho, lo único que sí es andar con mascarilla, con guantes".

Si bien con el inicio de la cuarentena se abasteció muy bien en el supermercado junto a su hija, y aun cuando declara que todavía le queda mercadería de esa compra, Rosita debe proveerse de lo necesario para la vida diaria. Para poder hacerlo y al mismo tiempo cuidarse, Rosita señala que "me aprovecho de mis vecinos". Esto quiere decir que se apoya en sus vecinos más jóvenes para proveerse de lo necesario, esto es gracias a que vive hace más de 40 años en su condominio y los conoce desde la infancia, destaca que son "cosas que uno siembra y después recoge". Este cuidado no solo nace de ella, sino que también de los propios vecinos quienes siempre le preguntan si necesita algo, e incluso le llaman la atención cuando la ven fuera de su departamento.

Rosita reconoce que ha experimentado cambios siendo el uso de internet central para hacer frente a la situación de confinamiento. Internet es el principal medio que la conecta con su trabajo, con Teresa, con su hija y nieta. En tiempos pre pandemia no tenía en su casa y solo conectándose en la casa de Teresa cuando trabajaban. Como en otras etapas de su vida, Rosita se ha adaptado y de a poco se ha aventurado en ese mundo virtual. Aprendiendo a revisar y enviar correos electrónicos y revisar la página web de impuestos internos. Esto lo aprendió viendo a Teresa y después se apoyó en su memoria. 
Rosita ha sorteado bien los cambios que le ha impuesto la situación de pandemia y el confinamiento, organizando su rutina diaria al espacio de su departamento, así de lunes a viernes trabaja y los fines de semana se dedica a descansar. Como es invierno, decidió acomodarse un espacio dentro de su dormitorio para trabajar, esto porque es un espacio más pequeño y puede calentarse más fácil, situación muy importante dada su artritis. Así ubica una pequeña mesa y una silla para revisar sus tareas, primero prepara los documentos a realizar en un cuaderno para después traspasarlos al computador. Destaca que la cuarentena le ha dado más tiempo para incursionar en el uso del computador, lo cual ha hecho sin problemas. Cuando Rosita no trabaja ve televisión y películas en la plataforma YouTube, lo cual es gracias a que su yerno le instaló un plan de internet en su casa. Si bien confiesa que a veces se siente sola, no le falta en qué entretenerse. Si no ve películas, pasa el tiempo leyendo la gran cantidad de libros que tiene en su casa. Los que si bien ya ha leído, leerlos nuevamente le da una visión diferente puesto que señala que "una cuando más edad tiene es otra manera de ver las cosas, va madurando".

Sin embargo, extraña las salidas y la posibilidad de ejercitarse. Como persona mayor dice necesitar el ejercicio por lo que trata de subir y bajar las escaleras de su edificio, además de esperar con ansias los días de permiso decretados por la autoridad en donde las personas mayores pueden salir una hora a la calle. El encierro ha sido difícil, incluso señala sentirse presa en su departamento. Situación que le recuerda el tiempo de los toques de queda durante la dictadura chilena donde no se podía salir. Pese a lo angustiante de la experiencia a Rosita no le faltó víveres, puesto que su madre tenía buenas relaciones con sus vecinos y un dueño de almacén que se los guardaba. De la misma manera, Rosita se apoya en sus redes de apoyo para sortear el actual momento de pandemia.

\section{Antonio: "Mejor que estés aquí no más, no importa que yo me enferme"}

Hace 13 años que Antonio recibe el pago de una jubilación anticipada, otorgada meses antes de enviudar, sin embargo, él continúa trabajando como conductor de buses. Vive en Santiago y sus días los divide entre dos residencias, su casa, donde convive con su hijo menor, su nuera y sus tres nietas, y el departamento de su pareja, Sonia. Cuenta que se mueve dependiendo de los horarios que se le 
asignen en su trabajo, en turnos nocturnos prefiere volver a su casa, mientras que en los turnos matutinos decide irse al departamento de Sonia.

Su experiencia de la pandemia se encuentra marcada por haberse contagiado en su trabajo. Los días anteriores a que se confirmara la positividad de su colega aprovechó de estar junto a sus nietas y realizar unos trabajos domésticos pendientes en su casa. Relata que con anterioridad habían llegado a un acuerdo con su pareja en que caso de que él se contagiara: "Lo conversé con ella. Le dije, bueno, ¿si me enfermo me vengo para acá o me quedo en mi casa? 'No, te venís [vienes] para acá', me dijo, 'yo sé que tenís [tienes] niños chicos allá, contagiado te van a mandar para otro lado después, mejor que estés aquí no más, no importa que yo me enferme"'.

Antonio afirma que de no haberse ido al departamento de su pareja, se hubiese trasladado a una residencia sanitaria, ${ }^{1}$ para no exponer a sus nietas a enfermarse. El día 12 de junio recibe el resultado del examen que confirma su contagio, y a pesar de las medidas de higiene y de la separación de camas con su pareja, a los dos días Sonia contrae el virus también. Cuenta que las infusiones de distintas hierbas fueron su mejor remedio, la hidratación fue necesaria para lidiar con la falta de apetito que tuvieron ambos durante semanas. Cincuenta días pasaron en confinamiento total, por lo que les fue necesario contar con una red de ayuda (familiares y vecinos) para conseguir insumos básicos. La hija de Sonia les llevaba alimentos y se los dejaba en la puerta, ellos se encargaban después de desinfectarlos y guardarlos.

A pesar de la ayuda de estos vecinos, Antonio cuenta que intentaron mantener en secreto su enfermedad por temor a la reacción de la comunidad, debido a que varias personas del edificio eran mayores y tenían problemas de salud graves: "si nosotros decimos que estamos contagiados, olvídate, queda la escoba. ${ }^{2}$ Capaz que nos hubieran sacado a nosotros dos de ahí y nos hubieran mandado a una [residencia sanitaria]". Esto nos habla de un cierto (auto)estigma por parte de Antonio que los lleva a ocultar su contagio con sus vecinos.

1 "Las residencias sanitarias son una estrategia para controlar la propagación del COVID-19. Está dirigida a las personas que han sido diagnosticadas con la enfermedad y que no pueden realizar una cuarentena efectiva en su domicilio" (Chile, 2020).

2 Expresión chilena que hace referencia a algo que generó un gran desastre. 
Si bien Antonio acostumbraba a pasar días en el departamento de su pareja, nunca había estado tanto tiempo allí encerrado, incluso nunca en su vida había tenido una experiencia similar de aislamiento. Afirma que lo peor del encierro es la ansiedad que genera no poder salir a caminar y la restricción de movimiento. Durante los casi dos meses de confinamiento total decidieron turnarse para realizar los quehaceres del hogar, para que esas tareas no recayeran únicamente en Sonia. El tiempo libre lo pasaban juntos escuchando música y viendo televisión; aunque Antonio asegura que, a pesar del encierro, cada uno tenía su propio espacio y pasatiempos personales. La reparación de muebles, aparatos y ropa fue uno de sus principales pasatiempos. Sin embargo, reconoce que la lectura de la Biblia fue y es su actividad diaria más importante: “yo siempre le pido a Él que me ayude. Lo más que pedía era que no me diera más fuerte para poder ver mis nietas y mis nietos que estén grandes, verlos crecer". El temor a la muerte se deja ver en las palabras de Antonio, y su estrategia o modo de afrontarlo es a través de su fe y creencia religiosa.

Relata que el distanciamiento con sus familiares lo pudo resolver a través de videollamadas con sus dos hijos para ver y saber de sus nietas y nietos. De modo que el conocimiento y manejo de los nuevos medios de comunicación virtual resultaron una herramienta fundamental al momento de mantener el contacto con sus seres queridos durante el encierro.

Finalmente, con el alta médica pudo volver a su casa y visitar a sus nietas "pero con mascarilla y de lejitos no más", dice. Con ello también regresó a las micros, y de acuerdo con lo que ha podido observar durante sus recorridos por la ciudad pronostica que el futuro se viene complicado por tres factores: las condiciones de inestabilidad económica, el resurgimiento de las protestas y la posibilidad de un rebrote por la desobediencia de la población a adoptar las medidas sanitarias.

\section{Conclusiones}

En este artículo nos hemos aproximado a la experiencia cotidiana de la vejez durante la pandemia, a través del análisis de tres casos de personas mayores que han desplegado una serie de estrategias y realizado ajustes y cambios 
en sus actividades diarias, ya sean laborales, familiares o afectivas. Asimismo, vemos de qué forma la situación sociosanitaria de los últimos cinco meses en el país ha ido reconfigurando la vida cotidiana en la vejez en la ciudad.

En los casos revisados aparece una resignificación del hogar como un espacio de intimidad en el cual se realizan nuevas actividades. Así, a las prácticas de cuidado propias del espacio familiar se suman prácticas de producción asociadas a otros espacios en tiempos pre pandemia. El "quedarse en casa" obliga a readecuar los espacios y las rutinas para sobrellevar la vida cotidiana constituyéndose en una nueva normalidad. En el caso de Rosita, su hogar se convierte en espacio laboral debiendo prepararlo para tal fin. Gema y Lalo se dividen los espacios para realizar sus rutinas diarias, Lalo en el jardín y Gema en el escritorio. En el caso de Antonio, debió cambiarse al hogar de su pareja. Esto nos muestra al hogar como una forma específica de organización social, un pequeño universo donde se articulan distintos mecanismos de producción, reproducción, distribución y circulación de normas, valores, recursos, conflictos y creencias (Elías, 1998 apud Cervio, 2020, p. 3). Pequeño universo que es atravesado por la pandemia y el confinamiento, produciendo cambios en la vida cotidiana de los interlocutores.

Dentro de estas experiencias de cambio, se observa -para los tres casos analizados- un quiebre en las relaciones y, contacto directo entre abuelos/as y nietos/as, que genera el confinamiento y aislamiento por las medidas de cuarentena. Esta separación responde, por una parte, a estrategias de cuidado y autocuidado de ambas partes ante los riesgos asociados al contagio del virus, optando por reemplazar el contacto físico-personal por otras formas de contacto basadas en la comunicación a distancia. Y por otra, a cumplir y respetar las medidas definidas por las autoridades en el país. Estas últimas, y la crisis sociosanitaria, han significado en la experiencia de los/las participantes de este estudio, una agudización de la desigualdad social, manifestadas en un doble estigma (Goffman, 1970). En primera instancia un estigma social que yace bajo la construcción de la identidad de las personas mayores en torno a estereotipos de fragilidad, dependencia, deterioro e inactividad; y en segunda instancia un auto estigma producido a partir de su autopercepción como persona mayor en riesgo de enfermar, o como en el caso de Antonio y su pareja, haberse enfermado y ser un posible vector de contagio para la comunidad. 
La feminización de los cuidados también está presente en los relatos. En el caso de Antonio, es su pareja Sonia quien cumple el rol de cuidadora, tomando decisiones y desplegando distintas estrategias para el cuidado; es ella quién provee su departamento como el espacio para que ambos pasen el periodo de su cuarentena, una vez que él se contagia. La estrategia de Sonia y Antonia muestra cómo estas se orientan a fines que pueden ser vista como irracionales: finalmente ambos se contagiaron. En el caso de Rosita, ella decide quedarse en su casa sola, no solo como una forma de autocuidado, sino de su hija, manteniendo el rol de cuidadora dentro de su familia.

Destaca la importancia de experiencias biográficas previas y aprendizajes para enfrentar la pandemia y el aislamiento que ésta les significa. Tal es el caso de Gema, Lalo y de Rosita que relacionan esta experiencia con lo vivido durante la dictadura militar, entendidas ambas situaciones como crisis sociales que impactan en sus vidas. Desde este punto de vista, la vejez y tener una trayectoria de vida más larga, se presenta como una fortaleza, dadas por la experiencia y la memoria. De igual forma, las creencias y el ethos religioso, de Antonio, han significado una articulación biográfica y fortaleza en su vejez.

Las diversas experiencias y estrategias que viven y despliegan las personas mayores en contexto de pandemia, no sólo dicen relación con su condición de vejez, sino que se cruzan con las diversas posiciones que ocupan en la estructura social (Bourdieu, 1997), ya sea el género, la clase social, el lugar de residencia, entre otros. Cada uno de los relatos etnográficos expuestos, nos muestran que las personas mayores poseen una serie de fortalezas, capacidad de agencia (Archer, 2003) y de tomar decisiones sobre sus propias vidas y salud, a pesar de ser definidas como población de alto riesgo en esta crisis sociosanitaria.

Lo anterior ofrece un marco interpretativo de la pandemia Covid-19, que articula aspectos epidemiológicos con aspectos sociales y subjetivos. En este sentido, reconocer la agencia de las personas mayores, así como las diferentes estrategias que despliegan en su vida cotidiana, permitirá abordar la situación pandémica y definir medidas sanitarias a partir de un enfoque integral donde se identifiquen fortalezas y debilidades que pueden aportar de forma más eficaz a la prevención y/o tratamiento de la misma. 


\section{Referencias}

ARCHER, M. Structure, agency and the internal conversation. Cambridge: Cambridge University Press, 2003.

ARMITAGE, R.; NELLUMS, L. B. COVID-19 and the consequences of isolating the elderly. The Lancet Public Health, [s. l.], v. 5, n. 5, e256, 2020.

BELTRÃO, J. F. Autonomia não se confunde com teimosia! Discriminação por idade em tempos de COVID-19. Boletim Cientistas Sociais e o Coronavírus, São Paulo, n. 26, 23 abr. 2020. Disponible en: https://anpocs.org/index.php/publicacoes-sp-2056165036/ boletim-cientistas-sociais/2340-boletim-n-26-cientistas-sociais-e-o-coronavirus. Acceso: 28 ago. 2020.

BERG-WEGER, M.; MORLEY, J. E. Loneliness and social isolation in older adults during the Covid-19 pandemic: Implications for gerontological social work. The Journal of Nutrition, Health \& Aging, Paris, v. 24, n. 5, p. 456-458, 2020.

BOURDIEU, P. Razones prácticas. Barcelona: Anagrama, 1997.

CATALDI, M. El aislamiento social en las personas mayores institucionalizadas en el marco de la Pandemia de coronavirus COVID-19. Margen, Buenos Aires, n. 97, p. 1-6, 2020.

CERVIO, A. En cuarentena, en casa. Prácticas y emociones durante el aislamiento social, preventivo y obligatorio por COVID-19 en hogares urbanos de Argentina. Buenos Aires: Consejo Nacional de Investigaciones Científicas y Técnicas: Centro de Investigación sobre Comunidad Local, Participación y Política Social: Centro de Investigaciones y Estudios Sociológicos, 2020.

CHILE. Ministerio de Salud. Residencias sanitarias. In: MINISTERIO DE SALUD. Santiago: Minsal, 2020. Disponible en: https://www.minsal.cl/residencias-sanitarias/. Acceso: 28 ago. 2020.

DOURADO, S. P. A pandemia de COVID-19 e a conversão de idosos em "grupo de risco". Cadernos de Campo, São Paulo, v. 29, supl., p. 153-162, 2020.

FUENTES-GARCÍA, A.; Y OSORIO-PARRAGUEZ, P. Una mirada a la vejez en tiempos de pandemia: desde el enfoque de curso vida y desigualdades. Revista Chilena de Salud Pública, Santiago de Chile, n. esp., p. 90-102, 2020.

GOFFMAN, E. Estigma: la identidad deteriorada. Buenos Aires: Amorrortu, 1970.

HENNING, C. E. Nem no mesmo barco nem nos mesmos mares. Cadernos de Campo, São Paulo, v. 29, n. 1, p. 150-155, 2020. 
HUENCHUAN, S. Covid-19: recomendaciones generales para la atención a personas mayores desde una perspectiva de derechos humanos. Ciudad de México: Comisión Económica para América Latina y el Caribe, 2020. Disponible en: http://104.207.147.154:8080/bitstream/54000/1122/1/covid-rev11.pdf. Acceso: 28 ago. 2020.

INSTITUTO NACIONAL DE ESTADÍSTICA. Censo 2017. Santiago de Chile: INE, 2017.

JONES, X. R. Covid-19: an exposition, with a focus on social isolation in the elderly (UK). Milton Keynes: The Open University, 2020.

OSORIO, P. La longevidad: más allá de la biología. Papeles del CEIC, Leloa, n. 22, p. 1-28, 2006.

PAIT, H. A vida dos "velhinhos", as conexões sociais e as lideranças institucionais. Boletim Cientistas Sociais e o Coronavírus, São Paulo, n. 26, 23 abr. 2020. Disponible en: https://anpocs.org/index.php/publicacoes-sp-2056165036/boletim-cientistas-sociais/2340-boletim-n-26-cientistas-sociais-e-o-coronavirus. Acceso: 28 ago. 2020.

PALACIOS, F. R. V. Miradas etnográficas del envejecer en la pandemia. Antropología Americana, Ciudad de México, v. 5, n. 10, p. 139-162, 2020.

SCHOLTEN, H. et al. Abordaje psicológico del COVID-19: una revisión narrativa de la experiencia latinoamericana. Revista Interamericana de Psicología, [s. l.], v. 54, n. 1, e1287, 2020.

TORRES-MARÍN, B. El derecho a envejecer con dignidad no se confina. In: ROBLEDO MARÍN, C. (ed.). La vejez: reflexiones de la post pandemia. Medellín: Opción Colombia, 2020. p. 225-233.

WILKIS, A. Apuntes sobre la noción de estrategia en Pierre Bourdieu. Revista Argentina de Sociología, Buenos Aires, v. 2, n. 3, p. 118-130, 2004.

WORLD HEALTH ORGANIZATION. Coronavirus disease 2019 (COVID-19): situation report 57. [S. l.]: WHO, 2020. Disponible en: https://www.who.int/docs/ default-source/coronaviruse/situation-reports/20200317-sitrep-57-covid-19. pdf?sfvrsn=a26922f2_4. Acceso: 28 ago. 2020.

Recebido: 30/08/2020 Aceito: 20/01/2021 | Received: 8/30/2020 Accepted: 1/20/2021 